\title{
APLICAÇÃO DE APRENDIZAGEM BASEADA EM PROJETO NA EDUCAÇÃO À DISTÂNCIAUMA EXPERIÊNCIA COM TCC
}

\author{
SAO PAULO/SP JUNHO/2018 \\ Sydney Manzione - ESPM - smanzione@uol.com.br \\ Tipo: Relato de Experiência Inovadora (EI) \\ Categoria: Métodos e Tecnologias \\ Setor Educacional: EDUCAÇÃO SUPERIOR
}

\begin{abstract}
RESUMO
O presente artigo apresenta uma experiência na utilização de modelos de Metodologia Ativa de Aprendizado realizada no curso de MBA em Marketing por EAD da Escola Superior de propaganda e Marketing - ESPM.

O resultado da experiência alia as facilidades da utilização da Educação à Distância - EAD (e suas características de amplitude e extraterritorialidade facilitando o acesso ao conhecimento e servindo até de elemento democratizador do ensino) com os modelos inclusivos das Metodologias Ativas de Aprendizado, destacando o Aprendizado Baseado em Projetos (PBL), que aproximam o aluno do conhecimento, permitindo-Ihe autonomia e gestão da própria educação.

O resultado dessa iniciativa se mostra exitoso e, mais que isso, permissor de novas iniciativas, provando que a aplicabilidade do método ativo via EAD é não só viável como eficaz.
\end{abstract}

Palavras-chave: Palavras Chave: Educação à Distância, EAD, Metodologias Ativas de Ensino, Aprendizado Baseado em Projetos, TCC

\section{AGRADECIMENTOS}

AGRADEÇO PELO APOIO E PARCERIA AO PROF.TATSUO IWATA, À PROFA. CRISTINA VALIUKENAS E EQUIPE, À PROFA. INÁ BARRETO, AOS COLEGAS DAS BANCAS DE AVALIAÇÃO, AOS MONITORES E AOS ALUNOS. 


\section{Introdução}

A conturbada transição pela qual passa a sociedade, evolução essa que se pauta na tecnologia, vem trazendo no bojo mudanças na forma de se encarar o aprendizado. As novas gerações, em especial a chamada Millenials (os nascidos a partir de 1990 designação dada por Strauss e Howe (1997)) tem formas mais dinâmicas e interativas de se relacionar e interagir com o ambiente.

Esses jovens hoje estão no ensino universitário, em graduação ou pós-graduação. É uma geração que já participa de um mundo digital desde seu nascimento, ou o nativo digital como definido por Prensky (2001), e são expostos à tecnologia, fator que faz com que suas relações sociais e forma de ver o mundo sejam por esse novo meio influenciadas (TAPSCOTT, 1997). Na esteira desse novo pensar, da criação de um novo mind set, essa geração desenvolveu a capacidade de lidar com diversas ações simultâneas e, até por isso, entendem que as interações sejam imediatas nos seus meios de comunicar (TAPSCOTT, 1997; PRENSKY, 2001).

O perfil das novas gerações faz o enfoque na educação mudar por completo. A sala de aula tradicional deixa de ser interessante, chegando a ser tediosa. A multiplicidade de lidar com tarefas e a ânsia por comunicação imediata fazem da geração uma forte candidata a refutar o sistema de educação vigente.

Na própria esteira da (re)volução tecnológica, a educação à distância passa a tomar corpo e dispor de meios tecnológicos mais atuais, permitindo a interação imediata professor-aluno, professor esse atingido pela tecnologia e pelos apelos das novas gerações: o papel da educação tem de ser revisto.

A tecnologia - e suas implicações sócio culturais - corre em paralelo com a evolução e crescimento da $E A D$, porém as demandas do ensino continuam a acontecer. A questão, passa a ter peso prático no repertório das percepções dos professores que assistem ao crescente desinteresse dos alunos por estudar e sua perda de autoridade (SANTOS; SOARES, 2011), ou seja, a transmissão de dados, sem a recepção correta, passa a cair por terra.

Nesse novo caldo cultural não se pode imaginar a constância dos métodos, como não se pode querer que haja desacordos metodológicos entre as formas de educação, vis a vis as demandas das novas gerações, desapegadas ao tradicional, pouco afeitas às antigas noções de carreiras profissionais. 
Querer que haja desenvolvimentos paralelos entre a educação presencial e a EAD é mero exercício intelectual inócuo. A convergência e a complementaridade se fazem necessárias. Mais que isso, urgentes. No caminho de se "modernizar" a educação, passa-se a usar de forma mais constante as chamadas Metodologias Ativas.

A utilização desses métodos em aulas presenciais ainda não é de uma tônica usual e quando se pensa em seu uso em EAD, o espanto é o obtido. A complementariedade dos métodos se faz necessária.

O objetivo do presente artigo é apresentar um caso de aplicação de metodologia ativa de aprendizado, na plataforma EAD

\section{Referencial Teórico}

\section{A Educação à Distância}

Para o presente artigo a Educação à Distância será encarado aqui como um meio altamente eficiente para a aplicação de metodologias ativas. Quase sem risco, pode-se afirmar que a EAD se tem mostrado altamente eficiente, desde que amparado em processos corretos.

Duas considerações se fazem necessárias para que se entenda o crescimento da EAD, primeiro delimitando sua atuação e, segundo, propondo sua penetração nos meios sociais.

EAD pode ser definido como a sigla de educação a distância, aqui entendida como a modalidade educacional em que as atividades de ensino-aprendizagem são desenvolvidas majoritariamente (e, em bom número de casos, exclusivamente) sem que alunos e professores estejam presentes no mesmo lugar, a mesma hora. (ABED 2013).

Repare-se que a definição não restringe o meio. Por ela entende-se que a educação à distância pode se utilizar de qualquer meio, qualquer veículo.

Para uma maior delimitação do termo, ousamos aplicar, por empréstimo, o conceito de elearning, sucedâneo e complementar da própria EAD. É Rosenberg (2007) quem propõe a definição:

e-learning é a utilização das tecnologias da Internet para distribuir um largo conjunto de soluções que permitem aumentar o conhecimento e as competências, seja em nível individual, seja em nível institucional.

Perceba-se que a definição de Rosemberg privilegia o meio, a tecnologia, não levando 
em conta distância ou tempo. De certa forma as definições, ao menos para nossos intentos, se complementam, uma vez que a primeira definição carecia do corte tecnológico para se encaixar na moldura conceitual em que hoje é percebido a educação à distância.

Um dos fatores que serve de solo fértil para o desenvolvimento da EAD é a necessidade propalada, independentemente da eficácia ou não, das políticas públicas de educação, do espraiamento da educação pelo país. Cada vez mais a sociedade demanda por educação e por aprimoramento de conhecimento.

As entidades de ensino, por sua feita, começam a extrapolar suas possibilidades físicas, no que tange a albergar mais alunos. Sem contar com o incremento de custos que vem atrelado ao processo. Com isso, ou melhor, sem as preocupações com evolução, pode se concentrar em seu maior ativo: a geração/divulgação de conhecimento.

O aumento de usuários de Internet - segundo o PNAD em 2015 chegava a 102,1 milhões de usuários - amplia a proliferação do acesso à tecnologia, que aliada à disponibilidade dos estabelecimentos em incrementar o uso do sistema EAD, criam o caldo primal ideal para a evolução do sistema.

\section{Metodologias Ativas}

O ambiente de ensino sofreu mudanças, como já vimos. A educação presencial deve passar por adaptações para conquistar seus estudantes, hoje mais desatentos, menos preocupados com a autoridade e com "conhecimento" a um clique.

A entidade de ensino passa a, constantemente, buscar sua sobrevivência como instituição. Ao mesmo tempo a comunidade vê seus problemas aumentarem ou se sucederem gerando um contexto que não permite que haja interferência do estudante, visto não ser preparado para essa dinâmica, ficando à margem dos fatos (CANDAU, 1991).

Visando atrair os estudantes para o conhecimento e buscando dar a eles autonomia em seu próprio aprendizado é que se desenvolvem as Metodologias Ativas, que são baseadas em maneiras de desenvolvimento do processo de aprendizado, por meio da utilização de experiências reais ou simuladas, buscando dar condições de, com sucesso, solucionar desafios advindos das atividades essenciais nos mais diferentes conceitos (BERBEL, 2011). 
A forma tradicional de transmissão de conhecimento, do professor ao aluno, perde o sentido com a Internet. Com isso o aprendizado pode acontecer independente de local ou tempo ou atores. E não há protocolos existentes de sucesso para o aprendizado nessa sociedade conectada (ALMEIDA e VALENTE, 2012). Com isso temos o campo para a evolução das metodologias ativas.

São listadas a seguir, algumas das principais, ou, ao menos, mais conhecidas, metodologias ativas: Método do caso; Aprendizagem Baseada em Problemas; Peer Instruction; Aprendizagem Baseada na Reflexão sobre a Experiência; Ensino com Pesquisa; Mapas Conceituais; Jogos Pedagógicos; Aprendizagem Baseada em Times. O de interesse presente é o Aprendizado Baseado em Projetos. Bender (2014) diz que a Aprendizagem Baseada em Projeto (PBL)

é a forma de permitir que os estudantes confrontem as questões e os problemas do mundo real que considerem significativos, determinando como abordá-los e, então, agindo de forma cooperativa em busca de soluções.

Nesse contexto devemos entender projeto como a ideia que envolve o sentido da antecipação de possibilidades factíveis e modificáveis no tempo, intrinsecamente voltadas para o novo, para aquilo que não se encontra previamente determinado, e que imprime sentido e direção à existência humana (BOUTINET, 2002) .

De uma forma reduzida (e até reducionista) podemos colocar o PBL num fluxo de atividades que se inicia, quando em grupos ou sozinhos, os estudantes investigam temas de interesse subordinados aos objetivos justificadores da disciplina envolvendo atividades desafiadoras e autênticas, realizadas com suporte de um método, criando condições que favorecem a aprendizagem significativa, capaz de colaborar para a autonomia e a criatividade dos participantes na medida em que há esforço autoral (BENDER, op. cit)

\section{Procedimentos Metodológicos}

Por método de exposição das ideias nesse artigo, optou-se pela exposição e análise de caso.

\section{Uma experiência: TCC em EAD com Aprendizado Baseado em Projeto}

Dentre os diversos cursos em EAD oferecidos pela ESPM - Escola Superior de Propaganda e Marketing -, nas modalidades de Pós-Graduação, existe o curso do MBA em Marketing. 
Como em qualquer curso superior há a exigência da apresentação, pelos alunos, de um TCC - Trabalho de Conclusão de Curso - a ser executado em grupo com, também, um trabalho individual.

Esse tipo de trabalho é desenhado para que os alunos lancem mão do aprendizado obtido durante o curso, sendo que a preocupação está mais em amalgamar os conhecimentos e dar a eles um caráter holístico.

No caso específico da ESPM optou-se por um Plano de Marketing, por ser uma forma de aplicação de, praticamente, todos os conceitos aprendidos durante o curso. Esse plano, para ter um caráter geral, deve partir de uma empresa existente, para a qual devese estipular todo o processo mercadológico.

A criação de tal plano sugere, de imediato, um projeto a ser entregue, composto de partes que vão sendo construídas, para se chegar a um produto final. Surgiu, dessa forma, o desafio de construir um projeto para o qual se deva dar orientação e que possa ser realizado em EAD, situação antes feita presencialmente.

Para a realização do projeto TCC em EAD, estipularam-se diversas operações que pudessem permitir sua execução. Dessa forma desenhou-se o que segue.

Infraestrutura: Para que o projeto se tornasse viável estipulou-se o uso da plataforma Blackboard que permite interação imediata ou remota professor-aluno. Para que houvesse efetividade, há um suporte tecnológico para manutenção do sistema. Do ponto de vista acadêmico um monitor acompanha o processo. Ele é responsável pela ligação do aluno ao processo, administrando horários, seções, materiais e tirando dúvidas não acadêmicas. Esse ambiente permite que haja segurança na interação dos players do processo.

Professor: o professor, inclusive como define o PBL, deve servir de parceiro, de facilitador e orientador do processo, sendo denominado professor orientador. Ele conduz o processo, orienta os caminhos e mostra os erros cometidos e os acertos esperados. Deixa claro aos alunos que não é parte do grupo, que irá orientar, mas não fará o trabalho em conjunto. Coloca-se como alguém que vai auxiliar o grupo no "enfrentamento" com a banca examinadora.

Fichas de acompanhamento: O curso tem, no caso da ESPM, 12 semanas de atividades e mais três para finalização antes da entrega final. Por se tratar de um projeto, a cada semana os grupos devem trabalhar uma das dez fichas apresentadas. 
Uma ficha, alma do processo, é uma sequência de orientações relativas a um dos capítulos de um plano de marketing. Esses passos, "orientadores", sempre deixado claro, devem ser trabalhados pelo grupo. Exemplificando: se uma ficha sugere análises baseadas nas cinco forças de Porter, o grupo deve vincular a teoria ao plano da empresa escolhida, apresentado as análises e os caminhos a serem adotados.

Orientação: A cada semana os grupos trabalham uma ficha. Suas análises e comentários, ainda sem preocupação com formatação, são apresentadas ao professor por escrito, via expedientes do Blackboard. Esse irá comentar o que foi realizado, apontando o que não está "correto" e o que está em linha com o esperado. Dará uma avaliação intermediária que serve, somente, de indicativo sobre o andamento do processo. Poderá ser avaliação por conceitos $A, B, C$ ou $D$, indicando desde o não aceitável (D) até o "continue assim" (A). É deixado claro que essa avaliação não comporá a nota final.

Aula "real time": A cada semana, após o feedback escrito, o professor faz uma Web Conference com os grupos. Nesse fórum, comentará a avaliação escrita e trocará ideias com o grupo, orientando e tirando dúvidas.

Dúvidas: As dúvidas acontecendo a qualquer momento, podem ser encaminhadas a um espaço específico, o fórum "pergunte ao professor". O professor recebe avisos em seu e-mail e responde em tempo hábil pré-estipulado. Todos os alunos têm acesso às perguntas e respostas. Eventuais questões particulares são encaminhadas por e-mail

Construção: A cada ficha os grupos vão acrescentando etapas que poderão ser revisitadas antes da montagem final do plano. Essa "montagem" final é apresentada ao orientador, em forma de rascunho, para seus últimos comentários antes da entrega do material para a banca avaliadora.

Banca avaliadora: O trabalho final é apresentado a uma banca composta de professores que, preferencialmente, tenham ministrado alguma disciplina à classe, por meio de uma apresentação resumo de 20 minutos. Os critérios de avaliação são, de antemão, apresentados aos grupos. Na figura 1 poderá ser visualizado o fluxo do processo.

Figura 1 - Fluxo de trabalho da aplicação de metodologia ativa em TCC usando EAD 


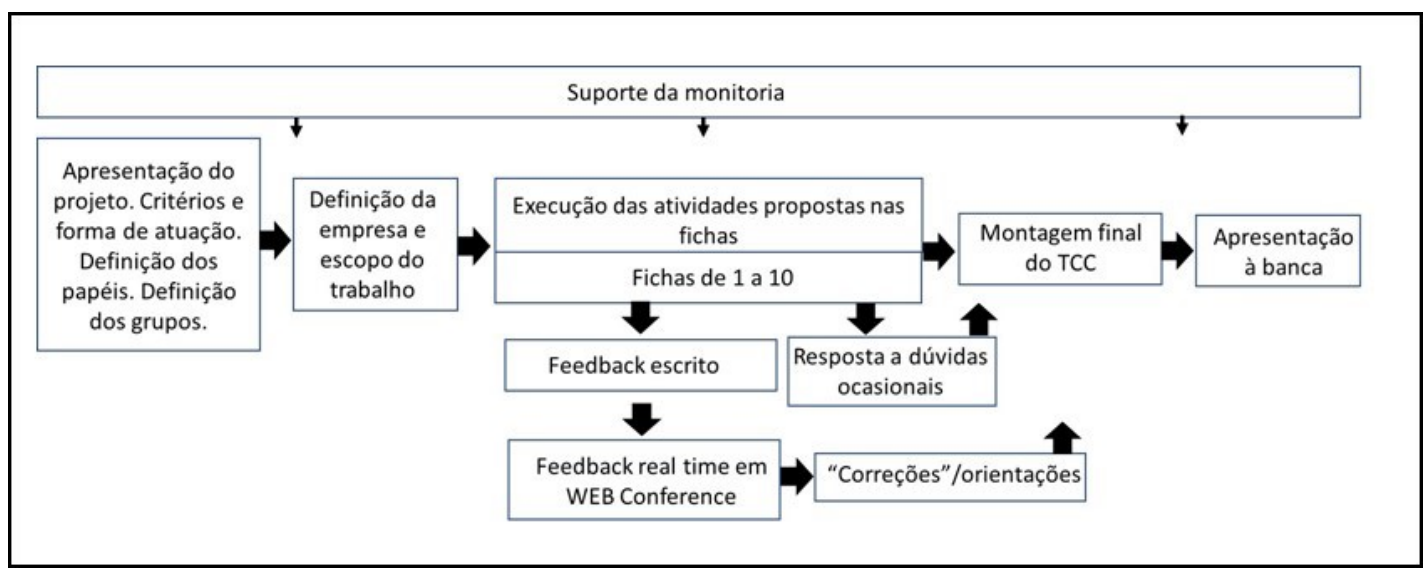

\section{Alguns achados e percepções}

Até o momento em que o presente artigo estava sendo escrito, 53 grupos de alunos já haviam sido avaliados. Esses grupos passaram por bancas compostas de diversos professores, tendo, sempre, o orientador como participante. As bancas aplicaram os critérios de avaliação com rigor, atribuindo notas aos trabalhos. A média de nota obtida pelos grupos já avaliados foi de 8,8, o que mostra que houve eficiência no método.

Do ponto de vista do orientador, o processo é complexo e exige atenção. O orientador deve se postar como um parceiro ajudando na construção do projeto como um todo. Não pode (e não deve) deixar de dar feedback, da mesma forma que não deve, pelos comentários, gerar desestímulo. A distância não pode ser uma escusa para a falta de relacionamento, que passa a ser estreito.

O orientador não pode, também, demorar em dar os retornos, pois, lembremos, os alunos se distribuem geograficamente espraiados e estão sem contato físico com colegas, instituição e professor.

Do ponto de vista dos alunos, percebe-se, paradoxalmente, que se estabelece contatos mais estreitos com a orientação, bem como fluxo mais ligeiro no processo de sanar dúvidas e em estabelecer contato. Os alunos, em geral, mostram satisfação com o método, mesmo porque, ao apresentar o trabalho, percebem que criaram um produto originado de pequenas peças que acompanham o projeto como um todo. Um fator positivo no processo é o aluno, que, em função de construir a partir de um projeto, tem um processo menos estressante, mais lúdico e, ao usar a EAD, tem contato mais rápido com a orientação, o que torna o trabalho final mais efetivo e focado.

\section{Conclusão}


A despeito do exercício ainda ser uma forma recente de aplicação, o resultado tem-se mostrado gratificante. Os comentários dos alunos, da monitoria e dos professores da banca têm sido positivos. Os trabalhos apresentam ótimo nível acadêmico e prático (ideia embutida no processo) com resultados muito relevantes. A experiência foi, dessa forma, exitosa. Os alunos tiveram uma sequência contínua e lógica de trabalho, obtiveram seus feedbacks e puderam construir trabalhos de qualidade. Um dos alunos declarou:

\footnotetext{
A metodologia... foi nova para mim. Já havia cursado um outro MBA cujo trabalho de conclusão utilizou metodologia diferente... nos permitiu construir semanalmente, passo a passo, as questões mais essenciais do trabalho, as decisões mais relevantes e depois desenvolvê-las de forma ampliada... Ao finalizar o trabalho, foi perceptível o quanto construí-lo desta forma tornou-se mais funcional, ainda mais em um grupo de um curso de ensino a distância que reuniu alunos em 5 cidades diferentes do Brasil que não poderiam se encontrar. Os feedbacks semanais, constantes e assertivos do orientador também foram fundamentais..., confirmado pela ótima avaliação do Plano de Marketing, tanto nos feedbacks da banca como na nota recebida. (Aluno do curso, 2017)
}

A soma das metodologias (EAD com Metodologias Ativas) se mostrou altamente eficaz. Havia um receio inicial quanto à eficiência de soma, mas os métodos apresentaram aderência e sinergia absolutas. $\mathrm{O}$ aluno se torna mais focado. A ele é dado um norte e um método que faz com que faça o aprendizado mais "leve". Acreditamos que iniciativas desse estilo, visto aqui se provarem eficazes, devem ser estruturadas e replicadas, pelo bem do ensino atual.

\section{Referências Bibliográficas}

ALMEIDA, M. E. B. de; VALENTE, J. A. Integração Currículo e Tecnologias e a Produção de Narrativas Digitais. Currículo sem Fronteiras., v.12, p.57 - 82, 2012. Disponível em: . Acesso em 10 ago. 2017

BERBEL, N. A. N. As metodologias ativas e a promoção da autonomia de estudantes. Ciências Sociais e Humanas, Londrina, v. 32, n. 1, p. 25-40, jan./jun. 2011

CANDAU, M. V. A didática em questão. Petrópolis: Editora Vozes, 1991.

Censo EAD - Relatório Analítico da Aprendizagem à Distância no Brasil - Associação Brasileira de Educação a Distância - ABED 2013 disponível em Acesso em 15 jun. 2017

PRENSKY, M. Digital natives, digital immigrants. Disponível em Acesso em 10 out. 2017

ROSENBERG, M. J. Beyond e-Learning: approaches and technologies to enhance organizational knowledge, learning and performance. San Francisco: Pfeiffer, 2006 
SANTOS, C. P. ; SOARES, S. R. Aprendizagem e Relação Professor-Aluno na Universidade: Duas Faces da Mesma Moeda. São Paulo: Est. Aval Educacional, v. 22, $n^{\circ} 49$, pp 353-370, maio/ago. 2011

STRAUSS, W., HOWE, N. The Fourth Turning. Nova lorque: Brodway, 1997

TAPSCOTT, D. Growing Up Digital: The Rise of the Net Generation. Boston: Harvard Business Press, 1997 